\title{
RCM 3 Methodology Application to Armored Military Vehicle Cooling System
}

\author{
Filipe Silva ${ }^{1}$, Énio Chambel $^{2}$, Virgínia Infante ${ }^{3}$, Luís Andrade Ferreira ${ }^{4}$ \\ 1Portuguese Military Academy, Rua Gomes Freire, Lisbon, Portugal \\ (filipecsilva14@gmail.com); 2Portuguese Military Academy, Rua Gomes Freire, Lisbon, \\ Portugal (enio.chambel@academiamilitar.pt) ORCID 0000-0002-4773-8227; 3Instituto \\ Superior Técnico, University of Lisbon, Av. Rovisco Pais, 1049-001 Lisbon, Portugal \\ (virginia.infante@tecnico.ulisboa.pt) ORCID 0000-0003-0860-2404; ${ }^{4}$ Fa culty of Engineering, \\ University of Porto, 4200-465 Porto, Portugal (Iferreir@fe.up.pt) ORCID 0000-0003-4667-8864
}

\begin{abstract}
The ultimate goal of developing the future of Reliability Centered Maintenance is to introduce the RCM3 methodology, applied in this article to the cooling system of high-performance military armored vehicles fleet, used in current operation theaters. This methodology is not only more advanced and aligned with the international standards for physical asset management and risk management, but also allows users to fully understand and quantify the associated risks, focused on the reliability of the systems. The case study aims to obtain a proposed maintenance plan to the vehicle's cooling system. Methods such as the distribution of Weibull applied to reliability and Right Censored Data, were used for the calculation of MTBF (Mean Time Between Failures). The results of the study confirm the possibility of using the proposed methodology to evaluate the operational reliability of the highperformance military armored vehicles fleet in any armed forces. The maintenance plan obtained with RCM3 proves to be more suitable and capable of reducing the risk associated with the system failure modes.
\end{abstract}

Author Keywords. Maintenance, Reliability, RCM3, FMECA, Armored Military Vehicle, Cooling System.

Type: Research Article

əे Open Access $\square \dot{~ P e e r ~ R e v i e w e d ~} @$ (i) CC BY

\section{Introduction}

The process of commercial vehicle exploitation can be analysed both in road transport companies, which operate in market conditions, as well as in rescue services and other services responsible for national security, such as the fire brigade, police, ambulance service, and army (Borucka, Niewczas, and Hasilova 2019). An important performance parameter is the failure frequency. The lower the failure frequency, the lower the costs of maintaining the fleet and the risk of failure to complete the task (Selech and Andrzejczak 2020).

There are currently several maintenance definitions in the literature, two of which are presented below.

The European standard EN 13306:2017 defines maintenance as "the combination of all technical, administrative and management actions performed during the life cycle of an item to maintain or restore it to a state where it can perform the intended function" (BSI 2017). In turn, the definition proposed by John Moubray in his book "RCM II - Reliability Centered Maintenance" (a reference work regarding the application of the RCM methodology) also adopted by Marius Basson in his book "RCM3: Risk-Based Reliability Centered Maintenance" (a current review of Moubray's work) considers that maintenance corresponds "to ensure that 
physical systems continue to do what their users want them to do" (Moubray 1999). In this way, it is easily perceived that maintenance allows maintaining the desired level of operability of a given system in service, to ensure that it can fulfill its function.

The Reliability Centered Maintenance methodology allows developing and optimizing maintenance programs for physical systems, and when correctly applied also allows to increase their reliability, which results in a series of other positive outcomes, such as the reduction of downtime, the decrease of associated costs, and the increase of safety and productivity. This methodology allows obtaining maintenance programs with a much lower amount of scheduled work than traditional methods and when used to revise already existing maintenance programs it allows obtaining a decrease in the amount of scheduled maintenance, usually in values around $40 \%$ to $70 \%$ (Moubray 1999).

The implementation of RCM3 analysis results in six important outcomes for the equipment, such as:

1. Defined operating context;

2. Inherent risk (associated with equipment operation and maintenance) quantified;

3. Maintenance schedules to be done by the maintenance department;

4. Revised operating and maintenance procedures;

5. Revised or residual risk after the implementation of the risk management strategies;

6. One-time changes (related to the design of the equipment or the way it is operated).

The demand associated with military missions combined with the degree of required readiness implies a great availability for the military equipment at service. In this way, maintenance undoubtedly plays an essential role in the proper functioning and reliability of equipment, being responsible for ensuring that it can fulfil its tasks when requested.

The military armoured vehicle referred to in this paper, is considered a weapon system of great importance for the army that owns it and for the fulfilment of its current missions. The cooling system of the armoured vehicle was chosen to be analysed in this study because it is one of the systems with the highest incidence of failures and improvement potential. In a total of 2038 analysed failures, 126 are related to the cooling system, which corresponds to about $6.2 \%$ of all weapon system failures.

Since RCM 3 is a very recent methodology (Basson 2018), there are only a few papers available in the literature regarding its application in real case studies. Therefore, this article appears to fill this lack of information, describing the application of the RCM3 methodology to armoured military vehicle cooling system, to review the suitability of the current maintenance plan, and identify suitable improvements.

\section{RCM3 Methodology}

The so-called 4th generation of maintenance is in line with the challenges presented by the 4th industrial revolution. This is the time of the "Internet of Things", "Smart Factories", "Big Data" and artificial intelligence, which has been breaking barriers and profoundly changing the industry as we knew it, and it is expected to improve productivity, safety, reliability, and quality of production. All these changes, of course, represent new challenges for maintenance, which appears to be a key element in today's organizations, with production philosophies highly dependent on production capacity (such as "just-in-time") and highly complex (high mechanization and automation of production) and numerous equipment. It is possible to conclude that the main objectives of this 4th generation of maintenance are to eliminate all failures, to ensure that the equipment meets its operating requirements throughout its useful life, to develop risk management strategies (both for assets and organizations as a whole), and 
to develop preventive and predictive maintenance strategies capable of contributing to the achievement of all these objectives (Basson 2018).

Maintenance managers face several challenges nowadays, like being able to select the most appropriate maintenance tasks for each equipment and situation (which may become complicated due to the rise of many new techniques and procedures, originate by the technological development), know how to deal with the equipment failure modes, find the best solution with the lowest associated cost, contribute to achieving the organization objectives without discouraging social and corporate responsibilities, being able to perceive how globalization may affect the results of their work and being able to take advantage of a large amount of information available today (Basson 2018).

The RCM methodology origin is related to the commercial aviation industry and arose from the need to increase the reliability of the aircraft and decrease the costs associated with their maintenance actions (Moubray 1999). The SAE JA1011 standard defines "RCM as a specific process used to identify the policies that must be implemented to manage the failure modes that can cause the functional failure of any physical system in a given operational context" (SAE 2009). The European standard BS EN 60300-3-11 states, in turn, that "RCM is a method for identifying and selecting fault management policies to efficiently and effectively achieve the desired safety, availability and economy of operation" (BSI 2009).

Finally, to define the RCM3 in concrete terms, its author, Marius Basson, assumes it as being "a process used to define the minimum necessary and safe number of maintenance actions, engineering and other risk management strategies to guarantee a tolerable level of safety, environmental integrity, and profitable operational capacity, as specified by the system management standards of the organization in which it is inserted" (Basson 2018).

In general, the RCM process is divided into 5 stages (Figure 1), which represent generically a synthesis of the logical sequence of work that must be performed during the implementation of this analysis (BSI 2009):

- Establishment and planning of the RCM;

- Functional failure analysis;

- Task selection;

- Implementation;

- Continuous improvement.

The RCM3 process requires 8 questions to be answered throughout its application (Basson 2018):

1. What are the operational conditions?

2. What are the functions and performance standards associated with the system in its current operational context?

3. How does the system fail to perform its functions?

4. What causes each failure state (failure modes)?

5. What happens when each failure occurs?

6. What are each failure associated risks (quantification of inherent risk)?

7. What should be done to reduce intolerable risks to a tolerable level (use of proactive risk management strategies)?

8. What can be done to reduce or manage the tolerable risks in an economically viable way? 
These questions summarize all the steps and information needed during the implementation of an RCM3 analysis, and when answered the analysis is completed and the process is concluded.

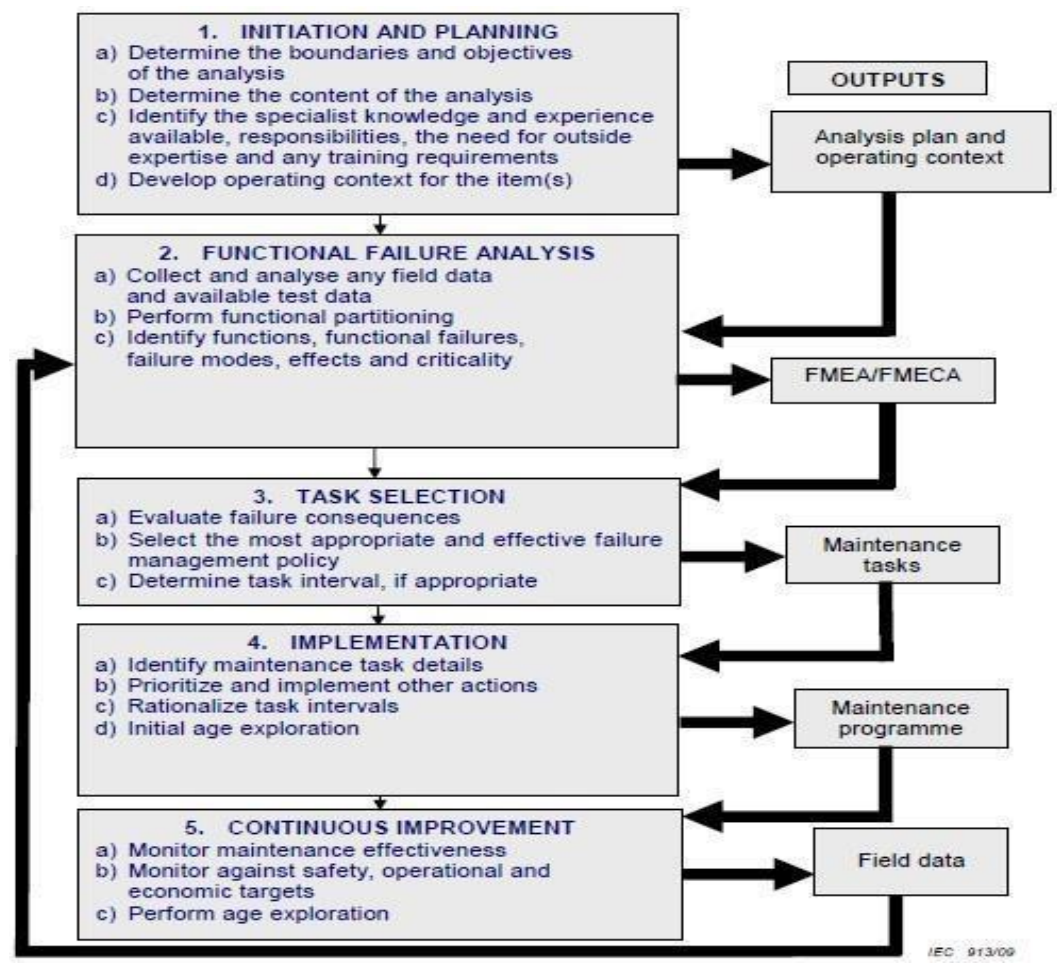

Figure 1: RCM Overview (BSI 2009)

\subsection{Comparison between RCM2 and RCM3 methodologies}

$\mathrm{RCM} 2$ has assumed itself as one of the most used and recognised methodologies in reliability maintenance process, having been applied to the most diverse areas. However (even being a very complete process) to keep up with the current needs and challenges that organisations are facing arose the need to change and develop originating the RCM3 methodology.

For those familiar with RCM2, the changes brought about by this new RCM3 may seem small or even insignificant, but they are a significant departure from the RCM process defined by SAE standard JA1011, presenting significant benefits and a change in the way it is interpreted and implemented. The RCM3 creates a strand for the definition of maintenance and risk management strategies. Reliability management has become highly specialised, and with the introduction of new standards and technology, RCM3 places reliability at the top of the organisation's management systems and is fully integrated with other Risk-Based approaches such as Risk-Based Inspection (RBI) and Root Cause Failure Analysis (RCFA) (Basson 2018).

RCM3 like RCM2 applies to all types of equipment and facilities, and both have a comprehensive scope of application to any type of process. However, RCM3 is a methodology that focuses primarily on identifying which risks are related to failures, then quantifying the risks, and finally identifying the best way to deal with those risks (Basson 2018). By considering physical (environmental and safety) and economic risk, the process is dealing with the risk as a whole, which makes it easier to reduce or eliminate the risk of the failing asset to a level that is perfectly tolerable by the organisation in which it operates (Aladon 2020a).

Aladon, the owner of the trademarks of the two methodologies, summarises the major differences between RCM3 and RCM2 as the following (Aladon 2020a): 
- RCM3 exceeds the SAE standards and expands RCM2's ability to align with the latest internationally accepted ISO Management Sys tems (ISO 55000 and ISO 31000)";

- "RCM3 is fully integrated with other Enterprise Risk Management Systems";

- "RCM3 is not just another initiative, it appears to be a business risk management process with the potential to become the most important management system to improve process security and asset integrity";

- $\mathrm{RCM} 3$ is the best response to the challenges and expectations presented by the 4 th generation of maintenance".

In Table 1 are resumed the improvements and advantages presented by RCM3 (compared to $\mathrm{RCM} 2$ ) concerning the most relevant RCM elements.

\begin{tabular}{|c|c|}
\hline RCM Element & Improvements and advantages \\
\hline Operating Context & $\begin{array}{l}\text { Defining the Operating Context (OC) is undeniable the first step of the RCM process } \\
\text { and all assumptions and decisions are based on the OC, making RCM3 compliant and } \\
\text { exceeding requirements of SAE standard. } \\
\text { Risk assessment and riskmanagement must be performed within the context - } \\
\text { according to ISO } 31000 \text { (ISO Standard for Risk Management). }\end{array}$ \\
\hline Functions & $\begin{array}{l}\text { Requirements for asset performance now includes el evated consideration for } \\
\text { sustainability and environmental integrity. The performance standard for initial } \\
\text { capability (inherent reliability) is now drawing the attention to defect elimination and } \\
\text { longer asset life while meeting regulations and regulatory requirements. }\end{array}$ \\
\hline Functional Failures & $\begin{array}{c}\text { Agreement between different disciplines (e.g., engineering, operations, and } \\
\text { maintenance) can be reached much faster and therefore the process of identifying } \\
\text { appropriate risk management strategies, is much quicker (saving time and money). } \\
\text { The new definition encourages the use of new maintenance techniques and } \\
\text { technology. }\end{array}$ \\
\hline Failure Modes & $\begin{array}{l}\text { Consistent and improved root cause failure identification is now possible, even for } \\
\text { inexperienced facilitators. Templating of like type equipment is easier to perform, } \\
\text { more information is carried over. Integration with other risk-based approaches (e.g., } \\
\text { RBI) are now easy to achieve. Root causes are identified and treated and no longer } \\
\text { the symptoms associated with failures. }\end{array}$ \\
\hline Failure Effects & $\begin{array}{l}\text { Easier and more comprehensive templating at equipment type level (Local Effect } \\
\text { descriptions included in the analysis template). Indicators easier to defi ne (clear } \\
\text { difference between what operator/maintenance personnel sees vs. what } \\
\text { management wants to see). } \\
\text { Potential worst case describes multiple failure conditions separate and with } \\
\text { appropriatelevel of detail. The focus is on increasing the reliability of the protected } \\
\text { function/system as a priority. It is now possible to quantify inherent risk and develop } \\
\text { risk mitigation strategies for intolerable risks. }\end{array}$ \\
\hline Consequence Vs Risk & $\begin{array}{l}\text { Improved integrity and improved planning for testing protective devices are possible. } \\
\text { The focus is on the devices that could impact safety vs. operations and improves the } \\
\text { understanding of the economic impact (of functional tests) and risk of the same. }\end{array}$ \\
\hline Decision Diagram & $\begin{array}{l}\text { The criteria for Hidden Economic Risks determine the optimum interval for failure } \\
\text { finding (providing highest availability) at the lowest cost. The cost of the failure- } \\
\text { finding taskmust still be acceptable to the user, otherwise a one-time change may be } \\
\text { considered to reduce the overall cost of multiple failures (where applicable). } \\
\text { Improved integrity through functional testing for protective systems that fail (based } \\
\text { on risk tolerance). The RCM3 decision diagram focus on the protected function as a } \\
\text { priority. These decisions areall risk based. }\end{array}$ \\
\hline $\begin{array}{l}\text { SAE JA } 1011 / 1012 \\
\text { International RCM } \\
\text { Standards }\end{array}$ & $\begin{array}{l}\text { RCM3 now aligns with new and emerging standards making the results easier to } \\
\text { defend. International standards and management systems are rarely challenged. } \\
\text { RCM3 will become the new standard }\end{array}$ \\
\hline
\end{tabular}

Table 1: Progression from RCM2 to RCM3, adapted from Aladon (2020b) 


\section{Failure Data Analysis}

For the application of the RCM methodology, it is essential the analysis of the existing failure data.

When analyzing failure data, it is usual to have poor quality (less relevant information or lack of data registration) or even incomplete information. Regarding existing data (whether from tests or actual operational context), it is practically impossible to obtain all the elements of a system, which requires estimates and approximations of the distribution parameters according to the available data. If all the systems/components are analyzed until the failure occurs (the failure time of all the components of the sample is known) the obtained data are complete. If in turn, there are components whose failure time is unknown (because it did not occur during the analysis period or because it is not possible to access the information) it is said that the data are censored (Rausand and Hoyland 2004).

A certain system failure time is said to be censored on the right (Figure 2), if its exact failure time is not known, and it is only known that it is going to fail after the final time of information recording (either the test completion time or the operational data collection limit time). In this case, we only know when the system is introduced in service, but not when it will fail (Rausand and Hoyland 2004).

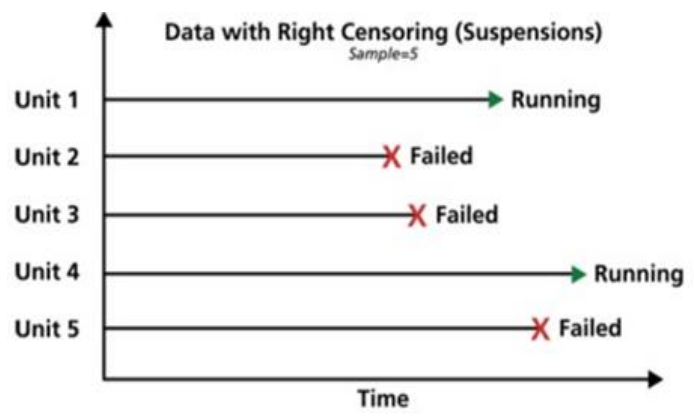

Figure 2: Right Censored Data (ReliaWiki, n.d.)

Right censored data can also be divided into Type 1 and Type 2 data (Rausand and Hoyland 2004):

- Type 1: Data collection ends after a predetermined time. Observation time is fixed.

- Type 2: Data collection ends after a predetermined number of failures occurs (defined at the beginning of the analysis).

\subsection{Weibull distribution}

There are currently available in the literature several probability distributions that can be used to model the useful life of a system. Despite the great variety of available mathematical models, this paper will address the Weibull distribution due to its characteristics becomes very versatile, constituting one of the most used models to represent systems life in reliability analysis (Murthy, Xie, and Jiang 2004).

Weibull's distribution corresponds to a semi-empirical expression developed by Ernest Weibull in 1939. It is a suitable distribution for systems with several components and for cases where the failure rate may or may not be constant (Gondim and Duarte 2005).

When analyzing data on probability plots, it can often be stated that they reflect more than one type of failure (e.g., fatigue, operational, construction, technological, etc.). In this case, all distributions ordered according to the aggregate selection method may turn out to be mismatched, because the developed method can only be used for a homogeneous type of failure of the examined component. In such situations, it is advisable to consider the possibility 
of using a mixture of distributions, a combination of two Weibull distributions (Selech and Andrzejczak 2020). This distribution can assume several shapes, and the standard model corresponds to the 2-parameter distribution (Gondim and Duarte 2005):

$$
F(t, \eta, \beta)=1-e^{-\left(\frac{t}{\eta}\right)^{\beta}}
$$

The location parameter $\eta$ corresponds to the lower limit of the domain $t$ considered and represents the asset life without failure, which means, the time interval for which no failure occurs. The shape parameter $b$ is a non-dimensional value, responsible for the shape of the distribution, and translates the mechanism of asset degradation, allowing to relate the distribution with the different asset life phases (Abernethy 2006):

- $b=1$ : the probability density function of the Weibull distribution takes the form of the exponential distribution. The failure rate is constant and given by $\lambda=1 / \eta$, which allows representing the useful life period;

- $B<1$ : the probability density function takes the form of the gamma distribution. In this case, the failure rate will be decreasing, which is suitable for the period of infant mortality;

- $B>1$ : the probability density function takes the form of the normal distribution (if $B=3.5$ ) or the log-normal distribution (if $B=2$ ). Here the failure rate is increasing, making it appropriate to represent the period of wear.

Once the reliability, $R(t)$, is the complement to the probability of failure, $F(t)$, it is possible to write (Murthy, Xie, and Jiang 2004):

$$
R(t)=1-F(t)=e^{-\left(\frac{t}{\eta}\right)^{\beta}}
$$

The probability density function, $f(t)$, of this distribution is represented as:

$$
f(t)=\frac{\beta}{\eta}\left(\frac{t}{\eta}\right)^{\beta-1} e^{-\left(\frac{t}{\eta}\right)^{\beta}}
$$

Considering equation (2) and equation (3), the failure rate, $\lambda(t)$, can then be defined, in terms of Weibull distribution, as follows:

$$
\lambda(t)=\frac{f(t)}{R(t)}=\frac{\beta}{\eta}\left(\frac{t}{\eta}\right)^{\beta-1}
$$

Another relevant reliability concept is Mean Time Between Failures (MTBF), which for the Weibull distribution is given by the average of the statistical distribution, which is described by the following equation (where $\Gamma$ is the gamma function):

$$
M T B F=\bar{T}=\eta \Gamma\left(\frac{1}{\beta}+1\right)
$$

It is possible to find in the literature several methods that allow estimating the parameters of the Weibull distribution, $\eta, 6$, in the case of the standard model of two parameters. These methods are essentially divided into two types: graphic methods and analytical (or statistical) methods (Murthy, Xie, and Jiang 2004).

\subsubsection{Graphic methods}

The graphic methods allow to simply obtain the parameters of the Weibull distribution through the graphical representation of the data corresponding to the failure times in analysis and are a good alternative to obtain a first approximation of the distribution parameters (Murthy, Xie, and Jiang 2004). According to Abernethy (2006) the "WPP" method - "Weibull Probability Plotting" is the most used graphic method to determine the Weibull distribution parameters, being widely used by most of the software currently available on the market. This method is based on the linearization of the accumulated probability function (equation (2)), 
which is obtained by performing twice the logarithm of that function, obtaining the following equations (Murthy, Xie, and Jiang 2004; Abernethy 2006):

$$
\begin{gathered}
\ln (R(t))=-\left(\frac{t}{\eta}\right)^{\beta} \\
\ln [-\ln (R(t))]=\beta \ln \ln (t)-\beta \ln (\eta)
\end{gathered}
$$

And so, we get the linearized accumulated probability function (equation (7)). Considering that:

$$
\begin{gathered}
Y(t)=\ln [-\ln (R(t))] \\
B=-\beta \ln (\eta) \\
X=\ln (t)
\end{gathered}
$$

Simplifying we obtain:

$$
Y(t)=\beta X+B
$$

This equation (11) allows determining the Weibull probability plot which is represented by a straight line when it is verified that the distribution fits the sample data set. This equation is obtained by linear regression of the set of points made up on the $X$-axis by the logarithm of the failure times (equation (10)) and on the $Y$-axis by the logarithm value of the accumulated probability of failure $(F(t))$ for each of the failure times (equation (7)). Without the values of $\eta$ and $B$, the value of $F(t)$ is unknown, and it is necessary to estimate it using the following estimators (equations (12) to (16)), where $i$ represents the order number of the failure time and $\boldsymbol{n}$ represents the total number of data corresponding to failure times (incrementally ordered) of the sample (Murthy, Xie, and Jiang 2004):

$$
\begin{gathered}
F(t)=\frac{i}{n} \\
F(t)=\frac{i}{n+1} \\
F(t)=\frac{i-0,5}{n} \\
F(t)=\frac{i-0,3}{n+0,4} \\
F(t)=\frac{i-\frac{3}{8}}{n+\frac{1}{4}}
\end{gathered}
$$

\subsubsection{Analytical methods}

Analytical methods can be considered more complete when compared with graphic methods, since they are more general and applicable to all types of models and data sets, and whose underlying theory allows a good understanding of the asymptotic properties of estimators (Murthy, Xie, and Jiang 2004). Several estimators in the literature can be used to determine the Weibull distribution parameters. This paper focuses on the Maximum Likelihood Estimator (MLE) method since it is one of the most widely used methods today due to its great versatility and capacity to produce reliable results. This estimator uses the maximization of the probability function of the statistical model in question (in this case the Weibull distribution) to obtain the parameters that characterize its distribution (Abernethy 2006; Ferreira and Silva 2017). 
In many cases, the probability function is very complex, and it is not possible to obtain an analytical solution which requires the use of numerical methods to obtain an approximate result (Abernethy 2006; Ferreira and Silva 2017). Resort to the literature it is possible to find the likelihood function for the distribution of Weibull (Held and Bové 2014):

$$
L(\eta, \beta)=\prod_{i=1}^{n} \frac{\beta}{\eta}\left(\frac{t_{i}}{\eta}\right)^{\beta-1} e^{-\left(\frac{t_{i}}{\eta}\right)^{\beta}}
$$

Since this is a monotonically increasing function, it is equivalent to maximizing the likelihood function or its logarithm, and in many cases, it is easier to maximize the logarithm than the likelihood function itself:

$$
\ln (L(\eta, \beta))=\sum_{i=1}^{n} \ln \left[\frac{\beta}{\eta}\left(\frac{t_{i}}{\eta}\right)^{\beta-1} e^{-\left(\frac{t_{i}}{\eta}\right)^{\beta}}\right]
$$

As previously mentioned, the objective of this model applied to the Weibull distribution is to determine the values of $\eta$ and $B$ that maximize the previous function, which can be done using numerical methods. It is also possible to apply this estimator to censored data sets. It is only present the equations corresponding to the application of the model for the Weibull distribution with Type 1 right-censored data because is used in this paper. For this case, the likelihood function is represented as follows (Held and Bové 2014):

$$
L(\eta, \beta)=\prod_{i=1}^{n}\left[\frac{\beta}{\eta}\left(\frac{t_{i}}{\eta}\right)^{\beta-1} e^{-\left(\frac{t_{i}}{\eta}\right)^{\beta}}\right]^{\delta_{i}}\left[e^{-\left(\frac{t_{i}}{\eta}\right)^{\beta}}\right]^{\delta_{i}}
$$

All that remains is to apply the logarithm to this equation for convenience and use a numerical method to maximize it.

\section{Case Study}

The case study consists of the application of all the steps defined by the RCM3 methodology to the armored military vehicle cooling sys tem, to obtain a maintenance plan.

The armored military vehicle cooling system is divided into 2 circuits, which are called a large cooling circuit and a small cooling circuit. The small circuit cools the engine and the hydraulic oil, transmission, and drive axels heat exchangers. In its turn, the large circuit cools the cooling fluid on the radiator.

\subsection{Operational context}

The first task to do after the definition of the system to be studied in RCM3 analysis is the definition of the operational context (Basson 2018). To define the operational context of the military armored vehicle was considered the climate conditions in which it operates (namely minimum, maximum, and average temperature ranges), roads and terrain conditions, and the average utilization of each vehicle of the fleet (measured in average Engine Hours per year).

\subsection{Functional analysis}

To be able to perform a functional analysis of the cooling system, it was necessary to identify the boundaries of the system, which means to identify which components are part of the cooling system and which ones will be analyzed. After this, all the system component's functions were identified and recorded in the proper sheets used to record all the RCM3 process information.

\subsection{Failure modes analysis}

After the functional analysis was carried out, the failure modes for each of the analyzed components were identified. This was done by recording all the failures that have occurred for this system (which corresponds to a total of 126 failures related to the cooling system in 
the period from January 2014 to April 2020). In addition to the failure modes identified in the failure occurrences, a critical analysis (engineering analysis) was also performed to complement the analysis with possible (and likely) failure modes for the components of the cooling system.

\subsection{Failure effects}

The description of the failure effects is a very important phase, as it provides the necessary information for the risk analysis that is carried out for each failure mode identified. In this description, as the name indicates, the consequences resulting from the failure modes have been defined, both the operational consequences and the warning signs of the occurrences and their estimated frequency (used to define the probability of the failure mode when performing the risk analysis). The frequency of occurrence of the failure modes has been evaluated by estimating their MTBF. For the failure modes with a lack of failure information, it was considered that its probability of occurrence was low.

Since the system had never been analyzed before, and there was no knowledge about its behavior or the life of its components, it was decided to use the Weibull distribution, due to its great versatility and ability to adapt to every probability distributions and life stages. To estimate Weibull distribution parameters (to estimate the MTBF values) was used the WPP method previously described in this paper, in section 3 . The reliability estimator used in this method was the Herd-Johnson estimator, which corresponds to equation (13) because it was the estimator that allows obtaining better results to this data set (higher $\mathrm{R}^{2}$ ).

With the results obtained by the WPP method, was then applied the Maximum Likelihood Estimator method, as was described previously in this paper section 3, to obtain a more accurate result for the Weibull distribution parameters, because the used failure data sets were a typical Type 1 right-censored data sets. The application of this algorithm (was used the Excel solver to maximize the maximum likelihood function) allowed to obtain the Weibull distribution and MTBF values presented in Table 2.

Attending to the available failure information, was possible to estimate the MTBF for 2 different components (referred to as component $A$ and $B$ ), and for 2 specific failure modes (related with 2 other components). The failure modes are assigned according to an identification code composed of a letter (which identifies the component) and a number (which identifies the failure mode).

\begin{tabular}{|c|c|c|c|}
\hline & $\begin{array}{c}\text { MTBF } \\
\text { (Engine Hours) }\end{array}$ & First Estimation & Obtained Parameters \\
\hline$A$ & 4134.37 & $\begin{array}{c}\eta=401.97 \\
\beta=1.38\end{array}$ & $\begin{array}{c}\eta=4330.66 \\
\beta=1.14\end{array}$ \\
\hline B & 3696.19 & $\begin{array}{c}\eta=382.30 \\
\beta=1.08\end{array}$ & $\begin{array}{c}\eta=267.94 \\
\beta=0.80\end{array}$ \\
\hline$C-1$ & 3478.83 & $\begin{array}{c}\eta=423.28 \\
\beta=1.42\end{array}$ & $\begin{array}{c}\eta=3742.36 \\
\beta=1.26\end{array}$ \\
\hline D-3 & 1827.43 & $\begin{array}{c}\eta=277.07 \\
\beta=1.03\end{array}$ & $\begin{array}{c}\eta=1514.86 \\
\beta=0.74\end{array}$ \\
\hline
\end{tabular}

Table 2: Right censored data results

\subsection{Risk analysis}

The risk associated with each failure mode identified was determined according to the proposed methodology by Marius Basson (2018) which defines the risk as a combination of the failure mode Severity and its Probability of Occurrence.

$$
\text { Risk = Severity } x \text { Probability of Occurrence }
$$


This methodology differs from the typical procedure used in traditional FMECA analysis, which considers the Risk Priority Number (RPN) method as the core factor of the analysis, and the only evaluation standard for the ranking of the failure modes associated risks. In turn, the RPN method considers the risk as a combination of the Severity, Probability of occurrence, and Detectability (Lvet al. 2020).

For this RCM3 analysis, it was created a specific risk matrix with 5 levels of Severity and 5 levels of Probability of Occurrence. The severity was classified under 4 parameters of consequences: Safety and Health, Environmental, Operational, and Economical. The combination of both these parameters allows to rank the risk in 25 different levels divided into 4 categories (low, medium, severe, and high). If the risk ranking corresponds to a severe or high classification, then it is unacceptable, and something must be proposed to reduce the associated risk.

\subsection{Risk mitigation strategies}

After the risk analysis, risk mitigation strategies were defined based on the RCM3 decision diagram.

\section{Results}

The obtained maintenance plan only varies in four new actions (which were not performed in the manufacturer's maintenance plan), and the alteration of the execution periodicity of two already existing tasks, which does not constitute a significant change concerning the procedures already carried out and rooted in the structure and maintenance routines of this equipment. The new proposed actions consist in changing the inspection frequency of 2 components of the system, inclusion of the periodic inspection of a component that was not previously inspected, a new functional check test and the inclusion of a scheduled replacement of a component which was not initially planned.

The maintenance plan foresees some preventive maintenance tasks (namely inspections and scheduled replacements of some components) and corrective (post breakdown) maintenance actions for most components, and no on-condition maintenance actions are carried out. The MTBF values calculated with the available failure information (which can be found in Table 2) are high values and show that the components to which they refer have a high life span (much higher than the average utilization of the vehicles). Also, the obtained Weibull distribution parameters show that those failures have a random failure profile ( $6 \approx 1$ for all the components and failure modes in Table 2) which makes failures impossible to predict. Resorting to existing life component databases, it is possible to check for several of the components that form a typical cooling system, that these are items with typically large MTBF values.

Drawing on literature, Yutko, Jerath, and Brennan (2010), carry out an analysis of the failure rate of complex vehicles, namely buses (which some models have the same engine us ed in the armored vehicle), and state in their data analysis for one of the models they analyzed, the replacement of the water pump for a usage of 347398 miles (approximately 559000 kilometers), and for another of the models, the execution of a repair action related to engine overheating (without detail) for a usage of 382026 miles (approximately 614811 kilometers). These results confirm the high lifetimes of the components associated with the cooling system of this type of equipment.

Also, Chan, Mui, and Woo (1997) studied the maintenance policy and reliability of the radiators of a fleet of buses, and report for this component that:

- Clogging of the fins by dirt is easily observable visually and that the maintenance under condition to be carried out is simply to carry out their cleaning; 
- Clogging of the radiator inner tubes can be detected by installing flow meters, but their high installation cost makes this impractical;

- Radiator leaks are difficult to predict but are easily observed if they occur.

They conclude that the adoption of predictive maintenance strategies to reduce the number of failures related to clogging and leaks in radiators proves to be impractical, and that considering the failure intensity of the studied radiators (which proved to be practically constant over time) from the economic point of view preventive maintenance appears to be unnecessary. However, from the engineering point of view, preventive maintenance is carried out on the cooling system (cleaning of radiators) when buses reach 6, 10 and 14 years old (coinciding with major overhauls of buses) (Chan, Mui, and Woo 1997).

James (2020) also carries out a literature review focused on the themes of reliability, availability, and maintainability, covering the mechanical, tribological, electrical and electronic aspects of automobiles, and concludes that there are some works related to the reliability and analysis of engine oil, but none has been identified on the analysis of transmission oil or coolant, which are also important for the overall reliability of the engine and vehicles. In this way it is possible to state that there is a lack of information in the literature on the use of oncondition maintenance relating to the components that make up a typical automotive cooling system. This combined with results (for the MTBF and Weibull parameters) obtained in this paper, corroborates the decision to apply corrective maintenance to most of these system components, and not condition-based maintenance, for instance.

The RCM3 application allowed to obtain a new maintenance plan for the cooling system (as it was referred in the previous paragraphs) which aims to reduce and mitigate the risk associated with the failure modes (for each component of the system) identified in this paper. Table 3 presents the initial and revised risk after the implementation of the RCM3, allowing to compare the effects of RCM3 in both maintenance plans.

Table 3 contains the main components of the cooling system (identified with a letter) and their failure modes (identified with a number) and for each failure mode the values of the initial and the revised risk ranking. The risk is ranked on a scale from 1 to 25 as stated in section 4 , and the letters that accompany the risk values indicate if the risk is medium (M), Low (L), or Severe (S). 


\begin{tabular}{|c|c|c|c|}
\hline Component & Failure Mode & Initial Risk & Revised Risk \\
\hline \multirow{3}{*}{ A } & 1 & $9(\mathrm{M})$ & $9(\mathrm{M})$ \\
\hline & 2 & $9(\mathrm{M})$ & $9(\mathrm{M})$ \\
\hline & 3 & $9(\mathrm{M})$ & $9(\mathrm{M})$ \\
\hline \multirow{2}{*}{ B } & 1 & $9(\mathrm{M})$ & $9(\mathrm{M})$ \\
\hline & 2 & $9(\mathrm{M})$ & $9(\mathrm{M})$ \\
\hline \multirow{5}{*}{ C } & 1 & $8(\mathrm{M})$ & $5(\mathrm{~L})$ \\
\hline & 2 & $9(\mathrm{M})$ & $9(\mathrm{M})$ \\
\hline & 3 & $6(\mathrm{M})$ & $6(\mathrm{M})$ \\
\hline & 4 & $6(\mathrm{M})$ & $6(\mathrm{M})$ \\
\hline & 5 & $17(S)$ & $9(\mathrm{M})$ \\
\hline \multirow{5}{*}{ D } & 1 & $17(S)$ & $9(\mathrm{M})$ \\
\hline & 2 & $17(S)$ & $9(\mathrm{M})$ \\
\hline & 3 & $13(S)$ & $9(M)$ \\
\hline & 4 & $13(S)$ & $9(\mathrm{M})$ \\
\hline & 5 & $17(S)$ & $9(\mathrm{M})$ \\
\hline \multirow{4}{*}{$\mathbf{E}$} & 1 & $3(L)$ & $3(\mathrm{~L})$ \\
\hline & 2 & $5(L)$ & $3(L)$ \\
\hline & 3 & $9(\mathrm{M})$ & $9(\mathrm{M})$ \\
\hline & 4 & $6(\mathrm{M})$ & $6(\mathrm{M})$ \\
\hline \multirow{6}{*}{$\mathbf{F}$} & 1 & $13(S)$ & 9(M) \\
\hline & 2 & $6(\mathrm{M})$ & $6(\mathrm{M})$ \\
\hline & 3 & $6(\mathrm{M})$ & $6(\mathrm{M})$ \\
\hline & 4 & $6(\mathrm{M})$ & $6(\mathrm{M})$ \\
\hline & 5 & $6(\mathrm{M})$ & $6(\mathrm{M})$ \\
\hline & 6 & $6(\mathrm{M})$ & $6(\mathrm{M})$ \\
\hline \multirow{5}{*}{ G } & 1 & $6(\mathrm{M})$ & $6(\mathrm{M})$ \\
\hline & 2 & $6(\mathrm{M})$ & $6(\mathrm{M})$ \\
\hline & 3 & $6(\mathrm{M})$ & $6(\mathrm{M})$ \\
\hline & 4 & $6(\mathrm{M})$ & $6(\mathrm{M})$ \\
\hline & 5 & $6(\mathrm{M})$ & $6(\mathrm{M})$ \\
\hline \multirow{3}{*}{ H } & 1 & $6(\mathrm{M})$ & $6(\mathrm{M})$ \\
\hline & 2 & $6(\mathrm{M})$ & $6(\mathrm{M})$ \\
\hline & 3 & $6(\mathrm{M})$ & $6(\mathrm{M})$ \\
\hline
\end{tabular}

\section{Conclusions}

This study has identified several improvement possibilities concerning the military vehicle cooling system, both in terms of the procedure related to the recording and processing of information related to failures, and in terms of the maintenance tasks carried out, which have resulted in a set of proposals that are believed to bring improvements to the execution and management of the maintenance of the armored military vehicle and which can also be extended to other armored military vehicles. Taking this into consideration, besides the proposed maintenance plan, this paper has identified the need to improve the recording of failures for this equipment:

- Obligation to include information about the failure mode in the failure records;

- Obligation to include Engine Hours, Kilometers and Power Train Hours information in the failure records;

- Definition of a generalized procedure to be used when opening and closing failure records so that the time they are open effectivelycorresponds to the time since the fault was detected until it was repaired. 
After the performed analysis, it is possible to conclude that this is a robust system, with several components with few or no failures, and in the case of the components with more recurrent failure modes, they present high MTBF values. In the case of the latter failure modes, the determination of the Weibull distribution associated with them revealed values of the parameter $B$ close to 1 , confirming that the failure rates reveal that the components are in the life stage, presenting random failures (very difficult to predict).

The manufacturer's maintenance plan also proved to be adequate, requiring only a few adjustments to mitigate the risks associated with the most recurrent failure modes. Another added value of this paper lies in the fact that it has shown that it is possible to perform an analysis of this kind, without the need for major investment and using tools available in the organization.

Regarding the application of the RCM3 methodology, it brought some differences compared to the RCM2 methodology, namely:

- The operational context of the equipment under analysis was taken into account, which allowed taking into account the operational demands and requirements associated with the use of the armored vehicle;

- Failure modes were divided into cause and mechanism, identifying the specific failure and the potential cause;

- The risk analysis and the decision diagram took into consideration the consequences and environmental sustainability;

- The description of the effects of the failure is more detailed and provides more information to support the decision;

- The RCM3 decision diagram itself presents some differences from the RCM2 decision diagram, in the way it proposes to handle and treat the risk, being more able to deal with current demands and challenges of organizations.

\section{References}

Abernethy, R. B. 2006. The New Weibull Handbook. $5^{\text {th }}$ ed. Florida: R. B. Abernethy.

Aladon. 2020a. "Aladon - Reliability Centered Maintenance (RCM)". https://www.thealadonnetwork.com/about-aladon/methodologies/reliability-centeredmaintenance-rcm/.

Aladon. 2020b. "Progression from RCM2 to RCM3 with Highlights". https://www.aladon.com/wp-content/uploads/2020/03/Progression-From-RCM2-ToRCM3-V1.0-818.pdf.

Basson, M. 2018. RCM3 $3^{T M}$ - Risk-Based Reliability Centered Maintenance. South Norwalk: Industrial Press.

Borucka, A., A. Niewczas, and K. Hasilova. 2019. "Forecasting the readiness of special vehicles using the semi-Markov model". Eksploatacja i Niezawodnosc 21, no. 4: 662-69. https://doi.org/10.17531/ein.2019.4.16.

BSI (British Standard Institution). 2009. Dependability management - Part 3-11: Application guide - Reliability centred maintenance. BS EN 60300-3-11: 2009. United Kingdom.

BSI (British Standard Institution). 2017. Maintenance. Maintenance terminology. BS EN 13306: 2017. United Kingdom.

Chan, L.-Y., L.-M. Mui, and C.-M. Woo. 1997. "Reliability analysis and maintenance policy of radiators for a large fleet of buses". Quality and Reliability Engineering International 13, no. 
3 (may): 117-26. https://doi.org/10.1002/(SICI)1099-1638(199705)13:3<117::AIDQRE81>3.0.CO;2-Y.

Ferreira, L. A., and J. L. Silva. 2017. "Parameter estimation for weibull distribution with right censored data using EM algorithm". Eksploatacja i Niezawodnosc 19, no. 2: 310-15. https://doi.org/10.17531/ein.2017.2.20.

Gondim, R., and M. Duarte. 2005. "Aplicação da estatística na Manutenção Preditiva". FAMAT Em Revista 5: 211-23.

Held, L., and D. S. Bové. 2014. Applied Statistical Inference: Likelihood and Bayes. SpringerVerlag. https://doi.org/10.1007/978-3-642-37887-4.

James, A. T. 2020. "Reliability, availability and maintainability aspects of automobiles". Life Cycle Reliability and Safety Engineering. Article in press. https://doi.org/10.1007/s41872020-00130-3.

Lv, Y., Y. Liu, W. Jing, M. Woźniak, R. Damaševičius, R. Scherer, and W. Wei. 2020. "Quality control of the continuous hot pressing process of medium density fiberboard using fuzzy failure mode and effects analysis". Applied Sciences 10, no. 13 (july): Article number 4627. https://doi.org/10.3390/app10134627.

Moubray, J. 1999. RCM II - Reliability Centered Maintenance. $2^{\text {nd }}$ ed. Oxford: ButterworthHeinemann.

Murthy, D. N., M. Xie, and R. Jiang. 2004. Weibull Models. New Jersey: John Wiley and Sons, Inc. https://doi.org/10.1002/047147326X.

Rausand, M., and A. Hoyland. 2004. System Reliability Theory: Models, Statistical Methods, and Applications. $2^{\text {nd }}$ ed. New Jersey: John Wiley and Sons, Inc.

ReliaWiki. n.d. "Life Data Classification". Accessed September 18, 2020. http://reliawiki.org/index.php/Life_Data_Classification.

SAE. 2009. SAE JA1011 - Evaluation Criteria for Reliability-Centered Maintenance (RCM) Process. Vol. 4970. United States of America.

Selech, J., and K. Andrzejczak. 2020. "An aggregate criterion for selecting a distribution for times to failure of components of rail vehicles". Eksploatacja i Niezawodnosc 22, no. 1: 10211. https://doi.org/10.17531/ein.2020.1.12.

Yutko, M. J., K. Jerath, and N. S. Brennan. 2010. "A failure rate analysis of complex vehicles". International Journal of Heavy Vehicle Systems 17, no. 1 (november): 76-98. https://doi.org/10.1504/IJHVS.2010.029624.

\section{Acknowledgments}

This work was supported by FCT, through IDMEC, under LAETA, project UIDB/50022/2020. 